\title{
Genetic and Genetic Expression Analyses of Clear Cell Sarcoma of the Kidney
}

\author{
Amy E. Schuster, Dominik T. Schneider, Michael K. Fritsch, Paul Grundy, \\ Elizabeth J. Perlman, and The National Wilms Tumor Study Group
}

The University of Maryland School of Medicine (AES), Baltimore, Maryland; Department of Pediatric Hematology and Oncology (DTS), Children's Hospital, Heinrich-Heine University Medical Center, Düsseldorf, Germany; Department of Pathology and Laboratory Medicine (MKF), University of Wisconsin, Madison, Wisconsin; Molecular Oncology Program (PG), Cross Cancer Institute, Edmonton, Alberta, Canada; and Children's Memorial Medical Center and the Robert H. Lurie Comprehensive Cancer Center of Northwestern University (EJP), Chicago, Illinois

SUMMARY: Clear cell sarcoma of the kidney (CCSK) represents a significant diagnostic and clinical challenge. In search of diagnostically useful or biologically significant genetic abnormalities, we screened 30 CCSKs from the National Wilms Tumor Study Group. Genetic gains and losses were analyzed using comparative genomic hybridization; loss of heterozygosity at $11 \mathrm{p} 15$ was studied using microsatellite analysis. Loss of imprinting (LOI) was studied using allele-specific expression or methylation analysis at the Apal polymorphic site for IGF2, Alul and Rsal sites for H19, and Cfo I site for SNRPN. Comparative genomic hybridization analysis revealed quantitative abnormalities in only 4 of 30 CCSKs. Two showed gain of 1q, one also showed loss of $10 \mathrm{q}$, and the other also showed loss of terminal $4 \mathrm{p}$. The other two cases demonstrated chromosome 19 loss and chromosome $19 p$ gain, respectively. All 22 cases informative for $11 \mathrm{p} 15$ showed retention of both alleles. Of 14 CCSKs informative for IGF2, six showed biallelic expression; all three CCSKs informative for H19 exhibited monoallelic expression. The normal imprint pattern was present in all six CCSKs analyzed for SNRPN methylation. These data demonstrate an absence of consistent genetic gains or losses in CCSKs using these methods. The high frequency of LOI for IGF2 in CCSKs (43\%) is comparable to that reported in Wilms tumors. The retention of imprinting at the SNRPN and $\mathrm{H} 19$ loci confirm that LOI is not a ubiquitous epigenetic change. This suggests that IGF2, a potent growth factor, may play a role in the development or progression of CCSK. (Lab Invest 2003, 83:1293-1299).

\begin{abstract}
Clear cell sarcoma of the kidney (CCSK) arises most often in children under 3 years of age and accounts for $4 \%$ of all childhood renal tumors (Beckwith, 1983). The histologic appearance of CCSK overlaps that of many other pediatric renal neoplasms whose treatments differ significantly. Unfortunately, no diagnostically useful immunohistochemical or genetic changes have been identified thus far in CCSKs. Genetic studies of CCSKs are limited, and no consistent genetic markers have been identified, largely due to its rarity and its failure to grow in tissue culture. Many pediatric soft tissue malignancies have been reported to contain diagnostically useful fusion transcripts derived from specific chromosomal translocations. To screen for potentially useful genetic abnormalities, we examined 30 CCSKs by comparative genomic hybridization (CGH). This technique does not require growth in tissue culture or availability of paired normal samples.

Genomic imprinting, the differential expression of parental alleles of a gene in somatic cells, is thought to
\end{abstract}

DOI: 10.1097/01.LAB.0000087850.69363.59

Received May 7, 2003.

Address reprint requests to: Dr. Elizabeth J. Perlman, Department of Pathology, Children's Memorial Medical Center, 2373 North Lincoln Avenue, Annex 203,

Chicago, Illinois60614. E-mail: eperlman@childrensmemorial.org play a role in human disease and cancer development. The most commonly studied imprinted genes are IGF2 and $H 19$, both located at $11 \mathrm{p} 15$, and small nuclear ribonucleoprotein polypeptide $\mathrm{N}$ gene (SNRPN), located within the region of $15 q 11-13$. Both IGF2 and $\mathrm{H} 19$ are imprinted in humans, with expression of the paternal IGF2 allele and maternal $\mathrm{H} 19$ allele (Ogawa et al, 1993; Rainier et al, 1993). SNRPN is maternally methylated and paternally expressed. Loss of imprinting (LOI) of IGF2 has been observed frequently in a variety of childhood and adult tumors (Feinberg, 1999) and has been implicated in Beckwith-Wiedemann syndrome, a congenital overgrowth disorder that predisposes patients to embryonal tumors (DeBaun et al, 1998). Sohda et al (1997) reported LOI of IGF2 in one of two CCSKs examined. We analyzed loss of heterozygosity (LOH) for IGF2 as well as allele-specific expression of IGF2, H19, and SNRPN in 18 CCSKs for which paired tumor and normal samples were available.

\section{Results \\ Comparative Genomic Hybridization}

Twenty-six of 30 (87\%) CCSKs lacked chromosomal gains or losses by CGH. Gain of $1 q$ and loss of $10 q$ were identified in Case $A ; 1 q$ gain and $4 p$ terminal loss were present in Case B (Fig. 1). Abnormalities 
A

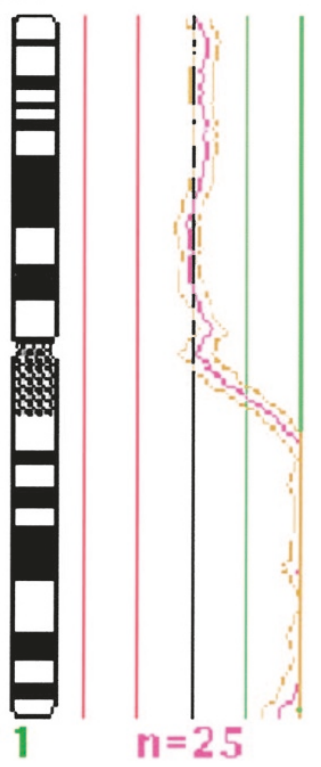

B

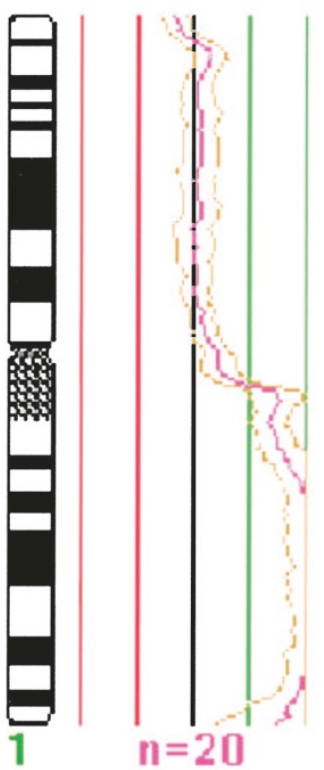

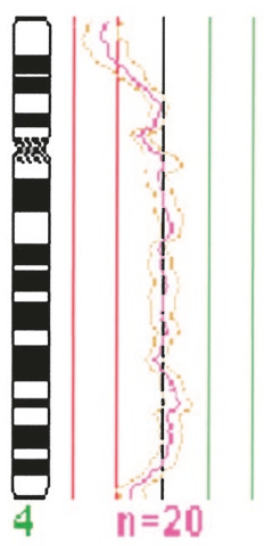

Figure 1.

Comparative genomic hybridization analysis of two cases of clear cell sarcoma of the kidney. Gain of genetic material is demonstrated by deviation of the ratio tracing from 1:1 (middle line) toward the right, and loss of genetic material results in deviation of the tracing to the left. The pink tracing is the mean, and the number of chromosomes used to generate the mean is indicated by $n$. The orange tracings to the left and right of the mean reflect the sem. (A) Tumor showing again of $1 q$ and loss of 10q. (B) Tumor showing gain of $1 \mathrm{q}$ and loss of the distal $4 p$.

of chromosome 19 were present in two additional cases, one with loss of 19 and one with $19 p$ gain. Reverse labeling confirmed both chromosome 19 abnormalities.

\section{Fluorescence In Situ Hybridization (FISH)}

To verify that gain or loss of chromosome 19 was not present in cases lacking abnormalities by $\mathrm{CGH}$, whole chromosome paint probes for chromosome 19 were used and confirmed the abnormalities demonstrated in the cases shown to be abnormal by $\mathrm{CGH}$. No additional cases with chromosome 19 gain or loss were uncovered. Whole chromosome paint probes for 1, 4, and 10 failed to distinguish separate signals within the interphase nuclei, and therefore were not useful in determining the presence or absence of balanced translocations at these loci in the cases lacking abnormalities by $\mathrm{CGH}$.

\section{LOH at $11 p 15$}

Of the 30 cases, 22 tumors were informative for either or both of the loci examined on 11p15, and all 21 demonstrated retention of both alleles in the tumor sample (data not shown).

\section{Allele-Specific Expression of IGF2 and H19}

In 18 patients, fresh frozen tumor samples were available for evaluation of IGF2 and H19 expression. Fourteen samples were informative for IGF2, and 6 of 14 samples showed biallelic expression (Fig. 2). Only two samples were informative at the $\mathrm{H} 19$ locus, and both

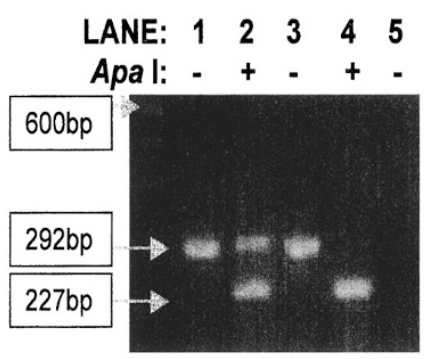

A

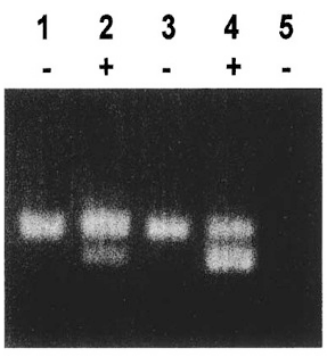

B
Figure 2.

Agarose gel showing the amplification products of IGF2 of two tumors, A and B. Lanes 1 and 2 show amplified DNA prior to and following digestion with Apal; Lanes 3 and 4 show cDNA before and after digestion with Apal. Lane 5 shows the negative control sample containing RNA amplified without reverse transcriptase. Tumor A demonstrates informativity following digestion (both 292- and 227-bp bands in Lane 2) and monoallelic expression (only the 227-bp band following digestion in Lane 4). Tumor B likewise is informative, yet shows biallelic expression (both the 227-bp and 292-bp bands present in Lane 4).

were monoallelically expressed (data not shown). The Rsal polymorphic site was then used to confirm the low informativity and retention of imprinting in CCSKs, and one additional informative case that likewise retained the normal imprinting pattern was uncovered.

Five patients exhibited biallelic expression of IGF2, yet were not informative for H19. One patient (no. 15) showed biallelic expression of IGF2 and monoallelic expression of H19. With the inclusion of Rsal, an additional CCSK was found to be informative at the H19 locus, which maintained monoallelic expression at both IGF2 and H19 loci (Table 1). 
Table 1. Expression of IGF2, H19, and Methylation Status of SNRPN in CCSKS

\begin{tabular}{|c|c|c|c|c|c|c|c|c|c|c|}
\hline \multirow[b]{2}{*}{ Case } & \multirow[b]{2}{*}{ Age (mo) } & \multirow[b]{2}{*}{ Sex } & \multirow[b]{2}{*}{ Stage } & \multicolumn{2}{|c|}{ IGF2-Apal } & \multicolumn{2}{|c|}{ H19-Alul } & \multicolumn{2}{|c|}{ H19-Rsal } & \multirow[b]{2}{*}{ SNRPN } \\
\hline & & & & DNA & RNA & DNA & RNA & DNA & RNA & \\
\hline 1 & Unknown & Unknown & Unknown & $a / b$ & b & $\mathrm{b} / \mathrm{b}$ & & $\mathrm{b} / \mathrm{b}$ & & $U+M$ \\
\hline 2 & Unknown & Unknown & Unknown & $b / b$ & & $\mathrm{a} / \mathrm{a}$ & & $a / a$ & & \\
\hline 3 & 15 & $\mathrm{~F}$ & 1 & $a / b$ & b & & & & & \\
\hline 4 & 7 & M & 4 & $b / b$ & & $b / b$ & & $b / b$ & & \\
\hline 5 & 25 & M & 2 & $b / b$ & & $\mathrm{~b} / \mathrm{b}$ & & $b / b$ & & \\
\hline 6 & 56 & M & 3 & $a / b$ & $b$ & $\mathrm{~b} / \mathrm{b}$ & & $\mathrm{b} / \mathrm{b}$ & & \\
\hline 7 & 13 years & M & 2 & $a / b$ & $a / b$ & $b / b$ & & $b / b$ & & $U+M$ \\
\hline 8 & 47 & $\mathrm{~F}$ & 3 & $a / b$ & $a / b$ & $\mathrm{~b} / \mathrm{b}$ & & & & $U+M$ \\
\hline 9 & 11 & $\mathrm{~F}$ & 2 & $a / b$ & $\mathrm{~b}$ & $\mathrm{~b} / \mathrm{b}$ & & $\mathrm{b} / \mathrm{b}$ & & $U+M$ \\
\hline 10 & 26 & M & 2 & $a / b$ & $a / b$ & $\mathrm{a} / \mathrm{a}$ & & $\mathrm{b} / \mathrm{b}$ & & \\
\hline 11 & 18 & M & 3 & $a / b$ & $a / b$ & $\mathrm{a} / \mathrm{a}$ & & $a / a$ & & $U+M$ \\
\hline 12 & 49 & $\mathrm{~F}$ & 3 & $a / a$ & & $b / b$ & & $b / b$ & & \\
\hline 13 & 8 & M & 3 & $a / b$ & $a / b$ & & & & & \\
\hline 14 & 11 & M & 2 & $a / b$ & $b$ & $a / b$ & b & $a / b$ & b & \\
\hline 15 & 102 & M & 3 & $a / b$ & $a / b$ & $a / b$ & $\mathrm{a}$ & $\mathrm{a} / \mathrm{b}$ & $\mathrm{a}$ & \\
\hline 16 & 31 & M & 3 & $a / b$ & $\mathrm{~b}$ & $\mathrm{a} / \mathrm{a}$ & & $a / b$ & b & $U+M$ \\
\hline 17 & 10 & M & 2 & $a / b$ & b & $b / b$ & & $b / b$ & & \\
\hline 18 & 28 & $\mathrm{~F}$ & 3 & $a / b$ & b & $\mathrm{a} / \mathrm{a}$ & & $a / a$ & & \\
\hline
\end{tabular}

$a$, allele containing no restriction site; $b$, allele with restriction site; $U$, unmethylated; $M$, methylated allele; CCSKs, clear cell sarcoma of the kidneys.

\section{Methylation Analysis of the 5' Flanking Region of the SNRPN Gene}

In six patients tumor DNA was analyzed for the methylation status of the $5^{\prime}$ flanking region of the SNRPN gene. All cases showed both the 340-bp band and 224-bp band at the expected 1.5:1 ratio as determined by Eagle Eye Systems. These results are consistent with somatic imprinting. The methylation status of three tumors biallelic for IGF2 were analyzed, and all demonstrated a methylated and an unmethylated SNRPN band (Table 1).

\section{Discussion}

The diagnosis of most pediatric renal tumors is aided by relatively specific histologic, immunohistochemical, or genetic features. This is not the case for CCSK, whose diagnosis is difficult and commonly missed. Our goal was to better characterize this rare entity with the hope of identifying diagnostically useful genetic abnormalities. There are limited reports available in the literature that shed light on genetic changes in CCSK, and these tumors typically demonstrate a normal karyotype (Choi et al, 1994). CGH analysis of four CCSKs found quantitative abnormalities in only one case, which showed $1 \mathrm{q}$ gain and $11 \mathrm{q}$ terminal gain (Barnard et al, 2000). The current study confirms the lack of quantitative genetic changes in a much larger series of CCSKs, with 26 of 30 cases demonstrating a normal CGH profile. Genetic abnormalities appeared in four cases, with a gain of 1q occurring twice. Gain of $1 \mathrm{q}$ is a common event in most types of childhood tumors and represents one of the most common changes identified in all cancers (Knuutila et al, 1998). Although the $11 \mathrm{q}$ terminal gain seen in the prior study was not apparent in our study, 10q loss and $4 p$ terminal loss occurred in conjunction with the 1q gain in two cases, and two cases demonstrated either loss or gain of chromosome 19. These findings contrast with studies of Wilms tumor, in which over $70 \%$ show genetic gains or losses by $\mathrm{CGH}$, with the median number of genetic changes identified being three (Hing et al, 2001). Of interest, gain of chromosome 1q, also identified in CCSK, was commonly seen in Wilms tumor and may be associated with relapse (Hing et al, 2001). Insufficient data are available to comment on the genetic gains and losses found by CGH in the two other pediatric renal tumor categories, namely rhabdoid tumor of the kidney and congenital mesoblastic nephroma. However, these two tumors are associated with characteristic and diagnostically useful genetic changes: $t(12 ; 15)$ is found in cellular congenital mesoblastic nephroma, and deletions or mutations involving the INI-1 gene are seen in rhabdoid tumors (Biegel et al, 1999; Knezevich et al, 1998).

The paucity of genetic abnormalities in this and other studies of CCSK suggests the possibility that a balanced translocation may play a role in its development. Balanced translocation are undetectable by $\mathrm{CGH}$ analysis. Cytogenetic analysis of one reported CCSK identified a balanced translocation, $\mathrm{t}(10 ; 17)(q 22 ; p 13)$ (Punnett et al, 1989). One sarcomatous Wilms tumor also had a similar translocation, $t(10 ; 17)(q 22 ; p 12)$ (Douglass et al, 1985). Balanced translocations with distinct fusion products have been identified in many pediatric tumors to date. The chromosome 10 abnormality seen in a single case from our series involved a breakpoint quite distant from 10q22. We attempted to investigate the possibility that balanced translocations involving loci at $10 \mathrm{q} 22,17 \mathrm{p} 13$, $4 \mathrm{p} 14$, and the chromosome 10 pericentromeric area were present in those tumors that by CGH demon- 
strated no gains or losses. However, we were unable to identify probes sufficiently near the potential breakpoint sites for evaluation. Further studies may be best addressed using spectral karyotyping or multicolor FISH performed on tissue culture samples to determine if these breakpoints are involved in a recurrent balanced translocation.

\section{Imprinting}

Genomic imprinting refers to the allele-specific expression of a gene. Imprinting is thought to be mediated by methylation of the promoter regions, the imprinting control region, or the silencer elements of the gene. Disruption of the methylation status at these sites may enable biallelic expression of the gene. The most commonly studied imprinted gene cluster resides on 11p15 and includes IGF2 and H19. IGF2 is an autocrine growth factor, and biallelic expression and increased levels of IGF2 transcripts are linked to the development of Wilms tumors and BeckwithWeidemann syndrome (DeBaun and Tucker, 1998; Ogawa et al, 1993). H19 mRNA is not translated into a functional protein, yet the transcript possesses growth suppressive activity when introduced into tumor cell lines (Hao et al, 1993). Down-regulation of the maternally expressed $H 19$ has also been seen in Wilms tumors (Steenman et al, 1994). It has been recognized that the expression of IGF2 and $H 19$ are co-regulated, and a boundary model has been recently proposed (Bell and Felsenfeld, 2000; Hark et al, 2000; Szabo et al, 2000).

The CCSK imprinting data presented in this study demonstrate a high frequency of LOI of IGF2 (43\%) and retention of the normal imprinting pattern for $\mathrm{H} 19$. This frequency of LOI at IGF2 is similar to that reported previously in Wilms tumors, although in Wilms tumors corresponding changes in $\mathrm{H} 19$ imprinting are seen (Ogawa et al, 1993; Taniguchi et al, 1995). Three other lesions (renal cell carcinoma, glioma, and hepatoblastoma) have shown LOI of IGF2 while maintaining the H19 imprint, in a pattern similar to that seen in CCSKs (Li et al, 1995; Oda et al, 1998; Uyeno et al, 1996). Monoalleic expression of $\mathrm{H} 19$ in conjunction with biallelic expression of IGF2 suggests that in some situations an independent imprinting mechanism also exists at this gene cluster. To our knowledge there has been no documented evidence of alteration of imprinting of IGF2 in rhabdoid tumors and congenital mesoblastic nephromas.

Lastly, the high frequency of LOI for IGF2 in Wilms tumors as well as CCSKs, two disparate tumors that may originate during fetal development, raises the possibility that during a finite period of normal renal development, LOI for IGF2 may occur. Persistence of this imprint would follow oncogenesis. Renal tumors developing during this period would then show LOI of IGF2, and this may or may not play a pivotal role in tumor development. This merits further analysis on the fetal kidney for allelic expression of IGF2.

\section{Conclusion}

Our results support a high proportion of normal profiles by CGH in CCSKs, and we uncovered changes in chromosomes 1, 4, 10, and 19 in a minority. The most common genetic event was 1q gain, which has also been detected in many other malignancies. Expression analyses confirm LOI of IGF2 in $42 \%$ of CCSKs, with retention of the normal somatic pattern at both the H19 and SNRPN loci.

\section{Materials and Methods}

\section{Specimens}

Paired normal and tumor DNA samples were obtained prior to treatment from 18 CCSKs in the National Wilms Tumor Study Group tumor bank. Tumor DNA alone was available for another 12 CCSKs. The diagnosis in all cases was confirmed by central pathology review. The presence of $>80 \%$ viable tumor cellularity was determined by histologic examination of the frozen tissue from which DNA was extracted. Tumors demonstrating $<80 \%$ tumor cellularity (those with abundant fibroblast or vascular component, common findings in CCSKs) were not analyzed. Genomic DNA was extracted using proteinase K/SDS followed by phenol/chloroform extraction and ethanol precipitation (Pitera et al, 1993).

\section{Nick Translation}

DNA (I ug) was labeled using DNA polymerase I and DNase, labeled dUTP (Spectrum Green for tumor and Spectrum Red for reference DNA; Vysis, Inc., Downers Grove, Illinois), dATP, dGTP, dCTP $(20 \mu \mathrm{m})$, Tris (50 $\mathrm{mm}), \mathrm{MgCl}_{2}$ (5 mm), mercaptoethanol (10 mm), and BSA $(10 \mathrm{ug} / \mathrm{ml})$ at $15^{\circ} \mathrm{C}$. Reaction time and DNase and polymerase amounts were adjusted to achieve DNA fragments between 500 and 1200 bp, as determined on a $1 \%$ agarose gel.

\section{CGH}

$500 \mathrm{ng}$ of labeled tumor and reference DNA were coprecipitated with 20 ug of COT-1 DNA and resuspended in hybridization buffer $(50 \%$ formamide, $\times 2$ SSC, and $10 \%$ dextran sulfate). The probe was denatured for 10 minutes at $75^{\circ} \mathrm{C}$, partially reannealed at $37^{\circ} \mathrm{C}$ for 30 minutes, and hybridized to methotrexatesynchronized reference metaphases on a glass slide, which was preaged 5 days, pretreated in $\times 2$ SSC for 1 hour at $37^{\circ} \mathrm{C}$, dehydrated in ethanol series, denatured at $70^{\circ} \mathrm{C}$ for 2 minutes in $70 \%$ formamide and $\times 2$ SSC, and dehydrated in cold ethanol series. Following application of the probe, slides were hybridized at $37^{\circ} \mathrm{C}$ for 3 days and postwashed for 5 minutes each in $\times 2$ SSC at $70^{\circ} \mathrm{C}, \times 2 \mathrm{SSC}$ at $37^{\circ} \mathrm{C}$, and $\times 2 \mathrm{SSC}$ and water at room temperature. Slides were counterstained with $0.1 \mathrm{ug} / \mathrm{ml} \mathrm{4',6-diamidino-2-phenylindole-}$ $2 \mathrm{HCl}$ in antifade (DAPI).

Gray-level images were acquired using the Applied Imaging Corporation's dedicated Cytovision software 
and hardware. Chromosomes were identified using reverse DAPI banding. Data from at least 20 representatives of each chromosome were analyzed to generate a mean ratio profile and standard error for each chromosome. Upper and lower thresholds of $>1.2$ and $<0.8$ were used as thresholds for gain or loss of chromosomal materials, respectively (du Manoir et al, 1995). Tumors showing concordant deviation of the profiles of lp, 19, and 22 were reanalyzed using reverse labeling.

\section{FISH}

Whole chromosome paint probes of chromosomes 1 , 4,10 , and 19 were made by DOP-PCR amplification from flow sorted whole chromosomes (Schrock et al, 1996). The probe was hybridized to touch preparations from frozen tissue, postwashed at $42^{\circ} \mathrm{C}$ in $50 \%$ formamide and $\times 2$ SSC for 20 minutes, $\times 2$ SSC at $37^{\circ} \mathrm{C}$ for 5 minutes and room temperature for 5 minutes, air dried and counterstained with DAPI.

\section{$\mathrm{LOH}$}

$\mathrm{LOH}$ analysis for $11 \mathrm{p} .15$ used primers that amplified a region of tyrosine hydroxylase and D11s1984. PCR reactions were performed using standard methods in a 50-ul volume with 100 ng of genomic DNA, 40 pmol of forward, 40 pmol reverse primer, and Taq polymerase (Pharmacia). PCR conditions for both primer sets included an initial denaturation for 5 minutes at $94^{\circ} \mathrm{C}$, 35 cycles at $94^{\circ} \mathrm{C}$ for 45 seconds, annealing at $57^{\circ} \mathrm{C}$ for 45 seconds, extension at $72^{\circ} \mathrm{C}$ for 45 seconds, and a final extension at $72^{\circ} \mathrm{C}$ for 5 minutes. The primers were custom prepared by Invitrogen, and the sequences used are provided in Table 2 . The PCR products were run on $8 \%$ nondenaturing acryalmide gels and were ethidium bromide stained.

\section{cDNA Synthesis}

Frozen tissue $(0.1 \mathrm{gm})$ was homogenized with TRIzol (Gibco BRL). RNA was extracted with chloroform, precipitated with isopropanol, washed with $80 \%$ ethanol, and air-dried. Pellets were dissolved in diethyl pyrocarbonate-treated water, and the extraction was repeated. The amount of RNA was quantified using UV spectroscopy, and the quality of the RNA was assessed by the identification of $28 \mathrm{~S}$ and $18 \mathrm{~S}$ bands on a $1 \%$ agarose gel. Following incubation with $1 \mathrm{U} / \mathrm{ul}$ of DNase (Boehringer-Mannheim), the RNA was reversetranscribed using superscript reverse transcriptase (Gibco BRL) and random hexamers (Perkin Elmer, Branchburg, New Jersey). The same amount of RNA after DNase treatment was amplified without superscript as the negative control for the RT-PCR reaction.

\section{Allelic Expression of IGF2}

The Apal polymorphism of exon 9 in the IGF2 gene was used to analyze allelic expression (Tadokoro et al, 1991). All amplifications were performed in a Perkin Elmer $2400 \mathrm{PCR}$ machine using $2.5 \mu \mathrm{M}$ of each primer (Table 2), 100 mм Tris- $\mathrm{HCl}$ (pH 8.3), 25 mм MgCl, 250 $\mathrm{mm} \mathrm{KCl,} 2 \mathrm{~mm}$ of each dNTP, and AmpliTaq Gold (Perkin Elmer). After initial denaturation for 10 minutes at $94^{\circ} \mathrm{C}$, amplification consisted of 30 cycles $\left(94^{\circ} \mathrm{C}\right.$ for 30 seconds, $60^{\circ} \mathrm{C}$ for 1 minute, and $72^{\circ} \mathrm{C}$ for 30 seconds) and one final extension at $72^{\circ} \mathrm{C}$ for 10 minutes. The amplification products were ethanol precipitated and digested overnight with $10 \mathrm{U}$ of Apal (New England BioLabs). Digestion products (10 ul) were separated on a $3 \%$ agarose gel. Because no introns exist within the amplified region, both the DNA and cDNA amplified products were $292 \mathrm{bp}$ prior to digestion. After Apal digestion, cases showing both a 292- and 227-bp DNA fragment were considered informative. The 65-bp fragment was not detectable on the agarose gels. The presence of both 292- and 227-bp fragments in the cDNA samples was indicative of biallelic expression.

\section{Allelic Expression of $\mathrm{H} 19$}

The Alul polymorphism in exon 5 of $\mathrm{H} 19$ was used to analyze allelic expression (Zhang and Tycko, 1992). All amplifications were carried out with $2.5 \mu \mathrm{M}$ each primer (Table 2), $100 \mathrm{~mm}$ Tris- $\mathrm{HCl}$ (pH 9.2), $15 \mathrm{~mm}$ $\mathrm{MgCl}_{2}, 250 \mathrm{~mm} \mathrm{KCl}, 2 \mathrm{~mm}$ of each dNTP, and Taq polymerase (Perkin Elmer). After an initial denaturation

Table 2. IGF2, H19, SNRPN, TH, and D11S1984 Primer Sequences Used for Amplification

IGF2.1 forward

IGF2.2 reverse

H19.1 forward

H19.2 reverse

H19.3 nested forward

H19.4 nested reverse

SNPI-51 forward

SNPI-32 reverse

SNPI-52 nested forward

SNPI-31 nested reverse

TH forward

$\mathrm{TH}$ reverse

D11S1984 forward

D11S1984 reverse

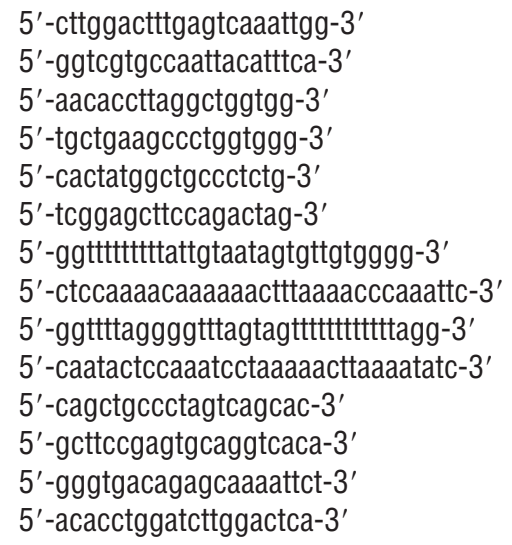


of 5 minutes at $94^{\circ} \mathrm{C}$, amplification continued for 20 cycles $\left(94^{\circ} \mathrm{C}\right.$ for 1.5 minutes, $56^{\circ} \mathrm{C}$ for 1 minute, $72^{\circ} \mathrm{C}$ for 1.5 minutes). The first amplification contained primers 1 and 2 in a 50-ul reaction volume, then $1 \mathrm{ul}$ was diluted in $49 \mathrm{ul}$ containing fresh reagents and primers 3 and 4 for another 20 cycles. Amplification products (DNA $833 \mathrm{bp}$ and cDNA $671 \mathrm{bp}$ ) were ethanol precipitated and digested overnight with $10 \mathrm{U}$ of Alul (Gibco BRL). Products were separated on a 3\% agarose gel. The DNA samples showing an uncleaved 300-bp band, a constant 261-bp band, and a 153- and 147-bp band were considered heterozygous. Biallelic cDNAs exhibited a constant 261-bp band and uncleaved 219-bp and 147-bp bands. The 76-bp, 72-bp, 60-bp, and 41-bp, 10-bp and 5-bp fragments were not apparent under the separating conditions. The size difference between the uncleaved DNA and cDNA fragment (300 bp and $218 \mathrm{bp}$, respectively) is due to two introns between exons 3 and 4 and exons 4 and 5 (Punnett et al, 1989). The Rsal polymorphism in exon 5 was used to confirm the low informativity of these tumors. The same primers and PCR conditions were followed as described. Amplification products were ethanol precipitated and digested overnight with $10 \mathrm{U}$ of Rsal according to the manufacturer's instructions (New England BioLabs). DNA digestion products with 833-bp and 693-bp bands were considered informative. Biallelic cDNA products exhibited both 531-bp and 140-bp bands.

\section{SNRPN Methylation Analysis}

Rather than expression analysis, the methylation status was used to determine the imprinting status of the SNRPN gene, because this approach allowed examination of all tumor samples. The Cfo I restriction site in the $5^{\prime}$ flanking region of SNRPN gene is methylated on the maternal chromosome in more than $96 \%$ of normal individuals and unmethylated on the paternal chromosome (Velinov et al, 2000; Zeschnigk et al, 1997). DNA modification was performed by overnight incubation with sodium bisulfite and hydrochinone (Intergen, Purchase, New York) followed by DNA extraction with glass beads. 250 ng of bisulfite-modified DNA were amplified with $100 \mathrm{~mm}$ Tris- $\mathrm{HCl}$ ( $\mathrm{pH}$ 9.2), 35 $\mathrm{mm} \mathrm{MgCl} 2,250 \mathrm{~mm} \mathrm{KCl,} 0.2 \mathrm{~mm}$ of each nucleotide, 1 $\mu \mathrm{M}$ of each primer, and 2.5 U TaqDNA polymerase (Taq Gold, Stratagene). Primer sequences used are shown in Table 2 . The primers bind to bisulfite modified DNA only, and the primer binding sites include no potentially methylated CpG dinucleotides, thus allowing amplification of both imprinted and nonimprinted alleles. A negative control with unmodified DNA was included in each experiment. After initial denaturation for 10 minutes at $94^{\circ} \mathrm{C}$, amplification proceeded for 35 cycles and 25 cycles, respectively, for nested PCR: 1 minute at $94^{\circ} \mathrm{C}, 1$ minute at $51^{\circ} \mathrm{C}$, and 1 minute at $72^{\circ} \mathrm{C}$.

The resulting 340-bp PCR product was digested overnight with $20 \mathrm{U}$ of Cfo I (Promega). The reaction products were separated on an ethidium bromidestained $2 \%$ agarose gel. To monitor the complete digestion, the H19-PCR product from genomic DNA was added to each reaction. Cfo I digests the 833-bp H19 product into 386-bp, 260-bp, 130-bp, and 57-bp fragments. Samples showing incomplete digestion were excluded from the analysis. PCR products from methylated (unmodified) alleles were digested into 224-bp and 116-bp fragments, whereas PCR products from unmethylated (modified) alleles resulted in an uncut 340-bp band. In the cases showing both bands, the relative band intensities of the ethidium bromide staining was accessed with the Eagle Eye Systems (Stratagene). As a result of the size difference between the two SNRPN bands, a 1.5:1 ratio was consistent with identical concentrations of both bands. In contrast, a ratio above 4.5:1 was considered a predominance of the unmethylated allele, and a ratio below $0.5: 1$ was considered a predominance of the methylated allele.

\section{Acknowledgements}

Supported by the Children's Cancer Foundation (EJP), UO1 CA42326 (EJP, PG), and by the Mildred Scheel grant from the German Cancer Aid (Deutsche Krebshilfe e.V.) (DTS).

\section{References}

Barnard M, Bayani J, Grant R, Zielenska M, Squire J, and Thorner P (2000). Comparative genomic hybridization analysis of clear cell sarcoma of the kidney. Med Pediatr Oncol $34: 113-116$

Beckwith JB (1983). Wilms' tumor and other renal tumors of childhood: A selective review from the National Wilms' Tumor Study Pathology Center. Hum Pathol 14:481-492.

Bell AC and Felsenfeld G (2000). Methylation of a CTCFdependent boundary controls imprinted expression of the Igf2 gene. Nature 405:482-485.

Biegel JA, Zhou JY, Rorke LB, Stenstrom C, Wainwright LM, and Fogelgren B (1999). Germ-line and acquired mutations of INI1 in atypical teratoid and rhabdoid tumors. Cancer Res 59:74-79.

Choi YJ, Jung WH, Jung SH, and Park C (1994). Clear cell sarcoma of the kidney-immunohistochemical study and flow cytometric DNA analysis of 7 cases. Yonsei Med J 35:336343.

DeBaun MR and Tucker MA (1998). Risk of cancer during the first four years of life in children from the BeckwithWiedemann Syndrome Registry. J Pediatr 132:398-400.

Douglass EC, Wilimas JA, Green AA, and Look AT (1985). Abnormalities of chromosomes 1 and 11 in Wilms' tumor. Cancer Genet Cytogenet 14:331-338.

du Manoir S, Schrock E, Bentz M, Speicher MR, Joos S, Ried T, Lichter P, and Cremer T (1995). Quantitative analysis of comparative genomic hybridization. Cytometry 19:27-41.

Feinberg AP (1999). Imprinting of a genomic domain of 11p15 and loss of imprinting in cancer: An introduction. Cancer Res 59(Suppl 7):1743-1746.

Hao Y, Crenshaw T, Moulton T, Newcomb E, and Tycko B (1993). Tumor-suppressor activity of H19 RNA. Nature 365: 764-767. 
Hark AT, Schoenherr CJ, Katz DJ, Ingram RS, Levorse JM, and Tilghman SM (2000). CTCF mediates methylationsensitive enhancer-blocking activity at the H19/lgf2 locus. Nature 405:486-489.

Hing S, Lu YJ, Summersgill B, King-Underwood L, Nicholson J, Grundy PE, Grundy R, Gessler M, Shipley J, and PritchardJones K (2001). Gain of $1 q$ is associated with adverse outcome in favorable histology Wilms tumors. Am J Pathol 158:393-398.

Knezevich SR, Garnett MJ, Pysher TJ, Beckwith JB, Grundy PE, and Sorensen PH (1998). ETV6-NTRK3 gene fusions and trisomy 11 establish a histogenetic link between mesoblastic nephroma and congenital fibrosarcoma. Cancer Res 58: 5046-5048.

Knuutila S, Bjorkqvist AM, Autio K, Tarkkanen M, Wolf M, Monni O, Szymanska J, Larramendy ML, Tapper J, Pere H, El Rifai W, Hemmer S, Wasenius VM, Vidgren V, and Zhu Y (1998). DNA copy number amplifications in human neoplasms: Review of comparitive genomic hybridization studies. Am J Pathol 152:1107-1123.

Li X, Adam G, Cui H, Sandstedt B, Ohlsson R, and Ekstrom TJ (1995). Expression, promoter usage and parental imprinting status of insulin-like growth factor II (IGF2) in human hepatoblastoma: Uncoupling of IGF2 and H19 imprinting. Oncogene 11:221-229.

Oda H, Kume H, Schimizu Y, Inoue T, and Ishikawa T (1998). Loss of imprinting of IGF2 in renal-cell carcinomas. Int $\mathrm{J}$ Cancer 75:343-346.

Ogawa O, Eccles MR, Szeto J, McNoe LA, Yun K, Maw MA, Smith PJ, and Reeve AE (1993). Relaxation of insulin-like growth factor II gene imprinting implicated in Wilms' tumour. Nature 362:749-751.

Pitera R, Pitera JE, Mufti GJ, and Salisbury JR (1993). Modification of standard proteinase $\mathrm{K} /$ phenol method for extraction of DNA from small tumour biopsies. Pathol Res Pract 189:882-887.

Punnett HH, Halligan GE, Zaeri N, and Karmazin N (1989). Translocation 10;17 in clear cell sarcoma of the kidney. A first report. Cancer Genet Cytogenet 41:123-128.

Rainier S, Johnson LA, Dobry CJ, Ping AJ, Grundy PE, and Feinberg AP (1993). Relaxation of imprinted genes in human cancer. Nature 362:747-749.
Schrock E, du Manoir S, Veldman T, Schoell B, Weinberg J, Ferguson-Smith MA, Ning Y, Ledbetter DH, Bar-Am I, Soenksen D, Garini Y, and Ried T (1996). Multicolor spectral karyotyping of human chromosomes. Science 273:494-497.

Sohda T, Soejima H, Matsumoto T, and Yun K (1997). Insulin-like growth factor 2 gene imprinting in clear cell sarcoma of the kidney. Hum Pathol 28:1315-1318.

Steenman MJ, Rainier S, Dobry CJ, Grundy P, Horon IL, and Feinberg AP (1994). Loss of imprinting of IGF2 is linked to reduced expression and abnormal methylation of $\mathrm{H} 19$ in Wilms' tumour. Nat Genet 7:433-439.

Szabo P, Tang SH, Rentsendorj A, Pfeifer GP, and Mann JR (2000). Maternal-specific footprints at putative CTCF sites in the $\mathrm{H} 19$ imprinting control region give evidence for insulator function. Curr Biol 10:607-610.

Tadokoro K, Fugii H, Inoue T, and Yamanda M (1991). Polymerase chain reaction (PCR) for detection of Apal polymorphism at the insulin like growth factor II gene (IGF2). Nucleic Acid Res 19:6967.

Taniguchi T, Sullivan MJ, Ogawa O, and Reeve AE (1995). Epigenetic changes encompassing the IGF2/H19 locus associated with relaxation of the IGF2 imprinting and silencing of $\mathrm{H} 19$ in Wilms tumor. Proc Natl Acad Sci USA 92:21592163.

Uyeno S, Aoki Y, Nata M, Sagisaka K, Kayama T, Yoshimoto $\mathrm{T}$, and Ono T (1996). IGF2 but not H19 shows loss of imprinting in human glioma. Cancer Res 56:5356-5359.

Velinov M, Gu H, Genovese M, Duncan C, Brown WT, and Jenkins $E$ (2000). The feasibility of PCR-based diagnosis of Prader-Willi and Angelman syndromes using restriction analysis after bisulfite modification of genomic DNA. Mol Genet Metab 69:81-83.

Zeschnigk M, Schmitz B, Dittrich B, Buiting K, Horsthemke B, and Doerfler W (1997). Imprinted segments in the human genome: Different DNA methylation patterns in the PraderWilli/Angelman syndrome region as determined by the genomic sequencing method. Hum Mol Genet 6:387-395.

Zhang $Y$ and Tycko B (1992). Monoallelic expression of human H19 gene. Nat Genet 1:40-44. 